\title{
Diseño de una máquina encapsuladora automática de comprimidos de gelatina dura de 500 miligramos
}

\author{
Design of an automatic capsule machine of 500 \\ milligrams hard gelatine tablets \\ Projeto de uma máquina automática de \\ encapsulamento para comprimidos de gelatina dura de \\ 500 miligramas
}

\author{
Luis Hidalgo-Solorzano ${ }^{\mathrm{I}}$ \\ luishsol@gmail.com \\ Fernando Palacios-Garcia ${ }^{\text {II }}$ \\ ferpalacios@gmail.com \\ Marco Navarrete-Villavicencio III \\ marconavarrevi@gmail.com
}

Recibido: 30 de enero de $2017 *$ Corregido: 20 de febrero de $2017 *$ Aceptado: 20 junio de 2017

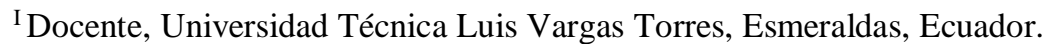

II Docente, Universidad Técnica Luis Vargas Torres, Esmeraldas, Ecuador.

III Docente, Universidad Técnica Luis Vargas Torres, Esmeraldas, Ecuador.
} 


\section{Resumen}

En el presente trabajo describimos las ventajas de las Cápsulas de Gelatina Dura, se explicará las generalidades sobre esta forma farmacéutica, sus ventajas y desventajas, sus componentes, los métodos utilizados para la fabricación, los equipos involucrados en la fabricación y algunos aspectos de importancia.

Para comprender más acerca de esta forma farmacéutica se empezará por describir la importancia de las cápsulas de gelatina dura.

Las cápsulas constituyen la segunda forma farmacéutica sólida de administración oral más frecuentemente utilizada, después de las tabletas.

Palabras clave: Máquina encapsuladora; farmacéutica; gelatina dura. 


\section{Abstract}

In the present work we describe the advantages of Gelatine Hard Capsules, we will explain the generalities about this pharmaceutical form, its advantages and disadvantages, its components, the methods used for the manufacture, the equipment involved in the manufacture and some aspects of importance.

To understand more about this dosage form will begin by describing the importance of hard gelatin capsules.

The capsules are the second most frequently used solid dosage form of oral administration, after tablets.

Key words: Encapsulating machine; pharmaceutical; hard gelatin. 


\section{Introducción.}

\section{Historia de la farmacia}

La industria farmacéutica surgió a partir de una serie de actividades diversas relacionadas con la obtención de sustancias utilizadas en medicina. A principios del siglo XIX, los boticarios, químicos o los propietarios de herbolarios obtenían partes secas de diversas plantas, recogidas localmente $\mathrm{o}$ en otros continentes. Éstas últimas se compraban a los especieros, que fundamentalmente importaban especias, pero como negocio secundario también comerciaban con productos utilizados con fines medicinales, entre ellos el opio de Persia o la ipecacuana de Suramérica. Los productos químicos sencillos y los minerales se adquirían a comerciantes de aceites y gomas.

Los boticarios y químicos fabricaban diversos preparados con estas sustancias, como extractos, tinturas, mezclas, lociones, pomadas o píldoras. Algunos profesionales elaboraban mayor cantidad de preparados de los que necesitaban para su propio uso y los vendían a granel a sus compañeros.

Algunas medicinas, como las preparadas a partir de la quina, de la belladona, de la digitalina, del centeno cornudo (Claviceps purpurea) o del opio (látex seco de la adormidera Papaver somniferum), eran realmente útiles, pero su actividad presentaba variaciones considerables. En 1820, el químico francés Joseph Pelleterier preparó el alcaloide activo de la corteza de la quina y lo llamó quinina. Después de este éxito aisló diversos alcaloides más, entre ellos la atropina (obtenida de la belladona) o la estricnina (obtenida de la nuez vómica). 
Su trabajo y el de otros investigadores hizo posible normalizar diversas medicinas y extrajo de forma comercial sus principios activos. Una de las primeras empresas que extrajo alcaloides puros en cantidades comerciales fue la farmacia de T.H. Smith Ltd. en Edimburgo, Escocia. Pronto los detalles de las pruebas químicas fueron difundidos en las farmacopeas, lo cual obligó a los fabricantes a establecer sus propios laboratorios.

\section{La industria farmaceútica}

La industria farmacéutica es un sector empresarial dedicado a la fabricación, preparación y comercialización de productos químicos medicinal para el tratamiento y también la prevención de las enfermedades, la cual reporta niveles de lucro económico altos. Algunas empresas del sector fabrican productos químicos farmacéuticos a granel (producción primaria), y todas ellas los preparan para su uso médico mediante métodos conocidos colectivamente como producción secundaria. Entre los procesos de producción secundaria, altamente automatizados, se encuentran la fabricación de fármacos dosificados, como comprimidos o pastillas, cápsulas o sobres para administración oral, soluciones para inyección, óvulos y supositorios.

Están sujetos a una variedad de leyes y reglamentos con respecto a las patentes, las pruebas y la comercialización de los fármacos. La industria farmacéutica es actualmente uno de los sectores empresariales más rentables e influyentes del mundo, lo cual produce al mismo tiempo elogios por sus contribuciones a la salud, y controversias por sus políticas de marketing y campañas para influir en los gobiernos, con el fin de aumentar los precios, extender sus patentes y con ello sus beneficios empresariales. Siendo acusadas por sus críticos de promoción de enfermedades, en algunos casos, al contribuir supuestamente a medicalizar los problemas derivados del modo de vida 
actual, al llamar la atención sobre condiciones o enfermedades frecuentemente inofensivas con objeto de incrementar la venta de medicamentos.

Muchas compañías farmacéuticas realizan tareas de investigación y desarrollo (I+D) con el fin de introducir nuevos tratamientos mejorados. En algunos países, cada etapa de pruebas de nuevos fármacos con animales domésticos (de granja o de laboratorio) o con seres humanos, tiene que recibir la autorización de los organismos reguladores nacionales. Si se produce la aprobación final se concede la autorización para utilizarlos en condiciones determinadas. En otros países se puede obtener el permiso de distribuir un fármaco presentando la autorización del país de origen.

Una gran parte de la producción de la industria farmacéutica corresponde a vacunas. La mayoría de las vacunas son inyectables, aunque algunas se administran por vía oral, en particular la vacuna de Sabin contra la poliomielitis, desarrollada a mediados de la década de 1950. Las vacunas protegen en el organismo sometiéndole a un agente patógeno debilitado, lo cual le ayuda a crear nuevos anticuerpos (inmunización a largo plazo) o proporcionándole anticuerpos activos (una solución más temporal).

La mayoría de los países conceden patentes para los medicamentos o fármacos recientemente desarrollados o modificados, por periodos de unos 15 años a partir de la fecha de autorización. Las compañías asignan una marca registrada a sus innovaciones, que pasan a ser de su propiedad exclusiva. Además, los nuevos medicamentos reciben un nombre genérico oficial de propiedad pública. Una vez que expira la patente, cualquier empresa que cumpla las normas del organismo regulador puede fabricar y vender productos con el nombre genérico. En realidad la industria farmacéutica es la principal impulsora de la extensión del sistema de patentes, y ha presionado a los países en desarrollo para hacerles seguir este sistema. 
La mayor parte de las empresas farmacéuticas tienen carácter internacional y poseen filiales en muchos países. El sector, tecnológicamente muy adelantado, da ocupación a muchos licenciados universitarios, como biólogos, bioquímicos, químicos, ingenieros, microbiólogos, farmacéuticos, farmacólogos, médicos, físicos y veterinarios, así como diplomados en enfermería. Estos profesionales trabajan en investigación y desarrollo (I+D), producción, control de calidad, marketing, representación médica, relaciones públicas o administración general. En 1994, las dos mayores empresas farmacéuticas del mundo eran la británica Glaxo y la norteamericana Merck \& CO. Cada una de ellas ocupa a unas 50.000 personas en todo el mundo, de las que unos 7.000 son licenciados universitarios.

Tanto las industrias cosmética y farmacéutica dan mucho énfasis al proceso de análisis de sustancias, elaboración y envasado de sus productos debido al gran uso por el ser humano hasta por los animales.

La elaboración de medicamentos a gran escala es otro de los principales cometidos de un farmacéutico.

La industria farmacéutica es una de las que más dinero mueve en el mundo hoy en día, de hecho las diferentes compañías farmacéuticas reciben grandes ingresos de sus medicamentos cuando los tienen bajo una patente. 


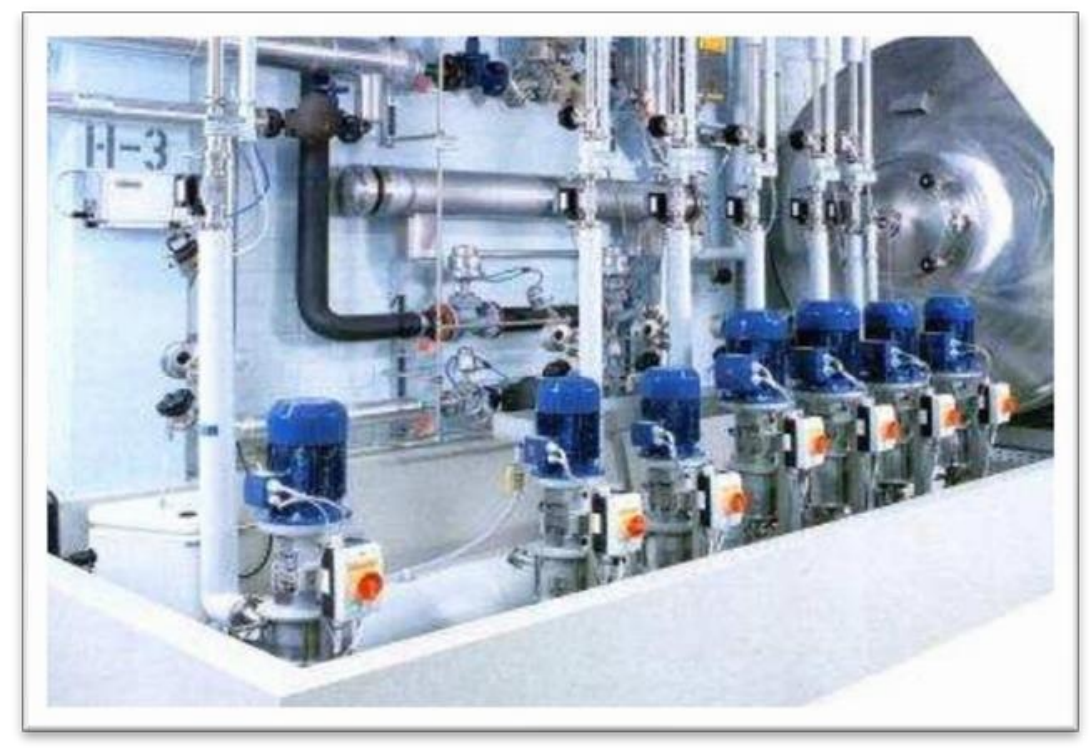

Figura 1. Industria farmacéutica Fuente: http://www.mancia.org/foro/articulos/77870-industria$\underline{\text { farmaceutica- crisis.html }}$

\section{La industria farmacéutica moderna}

Las compañías farmacéuticas fueron creadas en diferentes países por empresarios o profesionales, en su mayoría antes de la II Guerra Mundial. Allen \& Hambury y Wellcome, de Londres, Merck, de Darmstadt (Alemania), y las empresas norteamericanas Parke Davis, Warner Lambert y Smithkline \& French fueron fundadas por farmacéuticos. La farmacia de Edimburgo que produjo el cloroformo utilizado por James Young Simpson para asistir en el parto a la reina Victoria también se convirtió en una importante empresa de suministro de fármacos. Algunas compañías surgieron a raíz de los comienzos de la industria química, como por ejemplo Zeneca en el Reino Unido, Rhône-Poulenc en Francia, Bayer y Höchst en Alemania o Hoffmann-La Roche, Ciba-Geigy y Sandoz (estas dos últimas más tarde fusionadas para formar Novartis) en Suiza. La belga Janssen, la norteamericana Squibb y la francesa Roussell fueron fundadas por profesionales de la Medicina. 
Las nuevas técnicas, la fabricación de moléculas más complicadas y el uso de aparatos cada vez más caros han aumentado según las empresas farmacéuticas enormemente los precios. Estas dificultades se ven incrementadas por la presión para reducir los precios del sector, ante la preocupación de los gobiernos por el envejecimiento de la población y el consiguiente aumento de los gastos sanitarios, que suponen una proporción cada vez mayor de los presupuestos estatales.

\section{Situación actual}

La industria farmacéutica no afronta sola el coste de la investigación, ya que el sistema es mixto, con participación pública y privada. Las compañías aducen que la mayor contribución proviene de sus arcas, pero expertos independientes estiman que entre los gobiernos y los consumidores financian el $84 \%$ de la investigación en salud, mientras que solo el $12 \%$ correspondería a los laboratorios farmacéuticos, y un 4\% a organizaciones sin fin de lucro.

En cuanto al costo, según la versión de la industria, cada nuevo fármaco que ponen en el mercado requiere más de 800 millones de dólares en investigación. Sin embargo, un estudio que recopiló datos de 117 proyectos de investigación concluyó que el coste rondaría solamente 75 u 80 millones de dólares.

No obstante, las inversiones necesarias para el lanzamiento de un nuevo fármaco han experimentado un fuerte incremento debido al mayor número de ensayos clínicos necesarios antes de su comercialización. Este aumento es consecuencia de una legislación más estricta, que procura mejorar la seguridad de los pacientes, pero también del hecho de que los nuevos fármacos se parecen cada vez más a los antiguos, lo que obliga a realizar más pruebas para poder demostrar las pequeñas diferencias con el fármaco antiguo. 
De hecho según un estudio que revisó la documentación presentada ante la FDA estadounidense (organismo que autoriza la venta de medicamentos), sólo un 20\% de la inversión en investigación fue a parar a productos que aportan una mejora terapéutica notable.

\section{Los contaminantes}

Se ha alertado sobre los contaminantes orgánicos persistentes (COP), muy pocos conocidos y presentes en cosméticos y otros productos de uso cotidiano, dichas sustancias pueden influir en el organismo humano desde el momento de la gestación.

Muchas sustancias químicas se fabrican y comercializan sin tener información sobre los posibles efectos en la salud humana; en los últimos años se han incrementado las malformaciones y partos prematuros, así como enfermedades como cáncer, asma, trastornos del desarrollo y del sistema reproductor, desórdenes inmunológicos, etc.

El riesgo de padecer estos desórdenes se incrementa por la exposición a sustancias químicas presentes en los cosméticos, perfumes, esmalte de uñas, shampoo, jabones, etc. La mayor parte de estas sustancias analizadas son persistentes, permanecen en el medio ambiente en tales cantidades que se detectan continuamente; son bio-acumulables, lo que significa que se acumulan en el cuerpo de los organismos, en los tejidos adiposos o en otros órganos, como el hígado o los riñones.

Las sustancias peligrosas, incluso las perfectamente integradas en los productos que las contienen, pueden liberarse a lo largo del tiempo como consecuencia del uso, también pueden ser liberadas al medio ambiente durante su producción y cuando se convierten en residuos, al final de su vida útil. 
Este tipo de sustancias se encuentran sistemáticamente en los humanos (leche materna y sangre del cordón umbilical) lo que demuestra su descontrolada, amplia e indeseable dispersión; incluso los humanos nonatos están expuestas a estas sustancias peligrosas; una sola exposición a cualquiera de ellas probablemente no es perjudicial, pero si dicha exposición es diaria durante toda una vida, los efectos se acumulan.

\section{Registros sanitarios}

Para obtener ese registro es necesario tramitarlo ante el Ministerio de Salud u organismo correspondiente de cada país, aparte de eso para cada estado existen normas para realizar cualquier tipo de sustancia para ser comercializada, aun así hay que tomar en cuenta que existen unas normas generales dictadas por la Organización Mundial de la Salud.

Composición de las cápsulas de gelatina dura

La materia prima principal utilizada en la elaboración de las cápsulas es gelatina disuelta en agua desmineralizada. Posibles sustancias auxiliares o coadyuvantes, según el uso previsto de las cápsulas, son los plastificantes, colorantes, conservadores, humectantes y materiales gastrorresistentes.

La gelatina se obtiene hirviendo en agua piel, huesos de animales. La viscosidad y el poder gelificante o consistencia de la gelatina son dos propiedades esenciales para la fabricación de cápsulas.

Los plastificantes proporcionan la elasticidad y la flexibilidad de las cápsulas. Las de gelatina dura tienen menos de un 5\%, y las de gelatina blanda, entre un $20 \%$ y un $40 \%$. La glicerina es uno de los plastificantes más usados. 
La gelatina sea cual sea su origen para que sea oficial, debe de tener mínimo contenido microbiano, residuo en cenizas no superior al 1\%, arsénico en cantidades inferiores a una parte por millón, metales pesados no superiores a 50 partes por millón, agua no superior al $15 \%$ y $\mathrm{pH}$ entre 4.7- 6.0.

Los colorantes se utilizan para colorear las cápsulas y como opacificante se utiliza óxido de titanio. Los más frecuentes son la indigotina o índigo carmín y el amarillo de la quinolina. También se utilizan pigmentos como el óxido de hierro negro, rojo o amarillo.

Los conservadores se añaden para prevenir el crecimiento bacteriano y fúngico durante la fabricación. Destacan el dióxido de azufre y los parabenos.

Los humectantes sirven para facilitar la aplicación de los moldes de las cápsulas en la fabricación y para favorecer la disociación en el estómago. El más utilizado es el laurilsulfato de sodio.

Los materiales gastrorresistentes se utilizan para controlar la liberación intestinal de las cápsulas. Mezclados con la gelatina, proporcionan una cubierta entérica. Como materiales entéricos pueden mencionarse los derivados de la celulosa y los copolimeros acrílicos.

\section{Tamaños y capacidades}

Las cápsulas de gelatina dura están constituidas por dos partes cilíndricas, llamadas cuerpo o caja la más larga y en la que se aloja el fármaco, y tapa, tapadera o cabeza la que funciona como cierre de la cápsula. Se utilizan ochos tamaños distintos de cápsula, numerados del 000 (el mayor) al 5 (el más pequeño) (Fig. 2) 


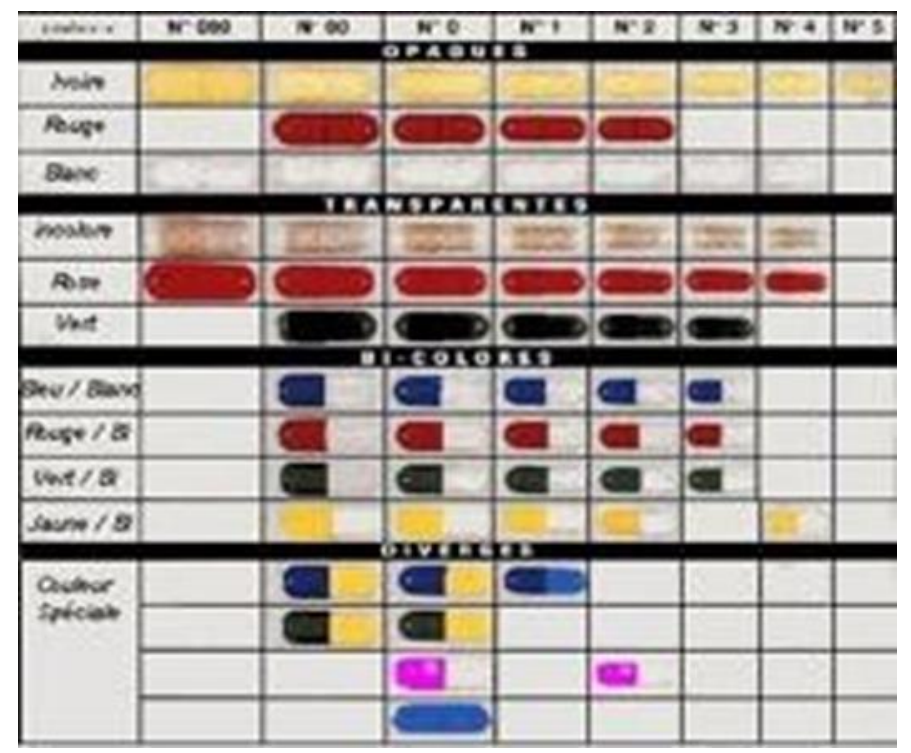

Figura 2. Tamaño de cápsulas fabricación de cápsula de gelatina dura

Fuente: http://www.tuinventas.com/attachments/article/356/Capsul\%20duras.pdf

La fabricación industrial de las cápsulas de gelatina dura comprende las siguientes etapas (Fig. 2)

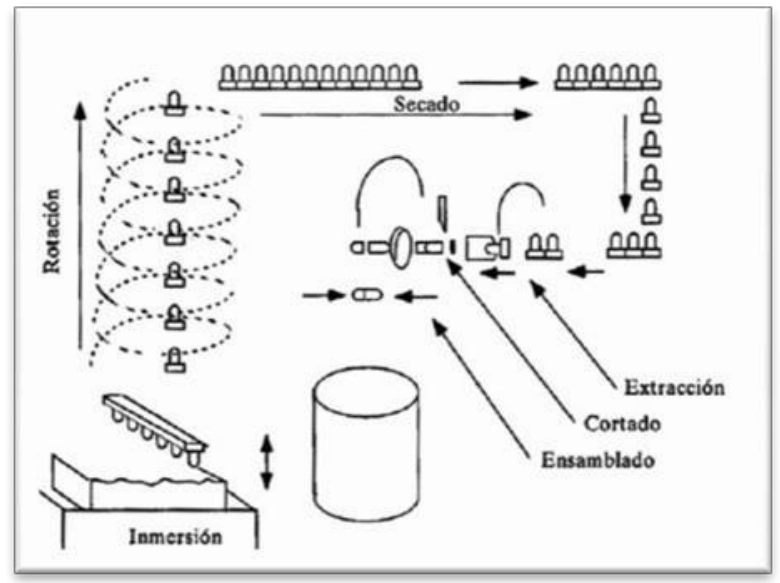

Figura 3. Esquema de proceso de fabricación de las cápsulas de gelatina dura

Fuente: http://medtrad.org/panacea/IndiceGeneral/n13-14 tradvterm-avascues.pdf

Preparación de la solución concentrada de gelatina $(30-40 \%$ en peso) en o agua desmineralizada (60- $70 \mathrm{C})$. 
Formación de las cápsulas por inmersión en la solución de gelatina, mantenida a temperatura constante (45-55oC), con punzones de acero inoxidable. Sobre la superficie de punzones o moldes, se forma una película por gelificación.

Secado de la película en estufas de desecación.

Extracción y ensamblado de los cuerpos y las tapas secos.

Preparación de la solución concentrada de gelatina (30-40\% en peso) en agua desmineralizada (60-70oC).

Formación de las cápsulas por inmersión en la solución de gelatina, mantenida a temperatura constante (45-55oC), con punzones de acero inoxidable. Sobre la superficie de punzones o moldes, se forma una película por gelificación.

Secado de la película en estufas de desecación.

Extracción y ensamblado de los cuerpos y las tapas secos

Para que no se separen fácilmente el cuerpo y la tapa de las cápsulas se han ideado diversos sistemas de cierre, como:

Sellado con una gota de gelatina o colocación de un precinto en la zona de contacto entre cuerpo y tapa.

Sistemas de autobloqueo, como Snap-Fix ${ }^{\circledR}$, Coni-Snap ${ }^{\circledR}$ o Star-Lock ${ }^{\circledR}$, consistentes en la formación de hendiduras y protuberancias complementarias en el cuerpo y en la tapa de la cápsula (Fig. 4). 


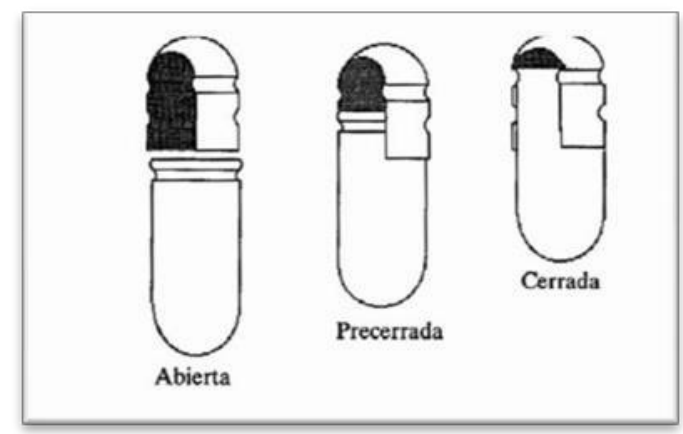

Figura. 4 Sistema cani-snap, de cierre de cápsulas de gelatina dura Fuente:

\section{http://medtrad.org/panacea/IndiceGeneral/n13-14 tradvterm-navascues.pdf}

Formulación de cápsulas de gelatina dura

Las cápsulas de gelatina dura suelen contener productos en polvo, microgránulos, gránulos o comprimidos; así como coadyuvantes. La única exigencia es que no reaccionen con la gelatina o dañen la integridad de la cubierta capsular.

Para asegurar el buen deslizamiento del polvo, se suelen incorporar al principio activo diversas sustancias auxiliares:

- Diluentes. Se incluyen lactosa, almidón, fosfato dicálcico, manitol y almidón de maíz pregelatinizado.

- Deslizantes. Como el dióxido de silicio coloidal con una concentración optima generalmente $<1.0 \%$.

- Lubricantes. Como estearatos metálicos, talco, polietilenglicoles 4000 y 6000 y ácido esteárico. 
- Humectantes. Sólo cuando en la formulación aparece una sustancia hidrófoba, se agregan humectantes adecuados tales como laurilsulfonatos, compuestos de amonio cuaternario, polisorbato 80, etc., en pequeñas cantidades.

Influencia de la cápsula en la velocidad de disolución de la forma farmacéutica en el lugar de absorción.

Las cápsulas son sustancias fisiológicamente indiferentes, el principio activo se va a comportar igual en presencia de la cápsula o sin esta, este es el modo ideal del comportamiento. La cápsula al desintegrarse puede ligar o aglomerar el polvo y retardar la disolución o la absorción. Este fenómeno se ha constatado en el caso de coloides con carga opuesta a la gelatina, para sustancias con afinidad a las proteínas, dando complejos que pueden ser poco solubles y por lo tanto poco absorbentes

Compuesto por dos elementos fundamentales: el principio activo y los coadyuvantes que pueden actuar como excipientes en cantidad suficiente. Los coadyuvantes normalmente pertenecen al grupo de diluentes, humectantes, absorbentes o aditivos. Los adsorbentes son usados para retener algo que pueda perjudicar al principio activo, los absorbentes son sustancias que favorecen la absorción de una tercera, los coadyuvantes serán utilizados solo cuando sea necesaria su presencia.

El principio activo es el eje de la formulación, con una acción terapéutica definida, acción que no debe ser modificada, así la solubilidad no variará la acción pero modificará el tiempo en que se pone en manifiesto. Hay que asegurar la eficacia, estabilidad y seguridad del principio activo en la forma que lo preparemos. 
En lo diluentes aparece la dificultad de dosificación debido a la dificultad del llenado, para evitar estas dificultadas recomendamos los siguientes puntos:

- Hay que determinar el volumen total de la formulación completa de la cápsula: principio activo y coadyuvante. Realizar las determinaciones reológicas de la mezcla de polvos como son:

- Tamaño y Distribución de Partícula

- $\quad$ Forma del polvo o granulado

- $\quad$ Fluidez (Determinado por el ángulo de reposo)

- Densidad Verdadera y Aparente

Velocidad de flujo

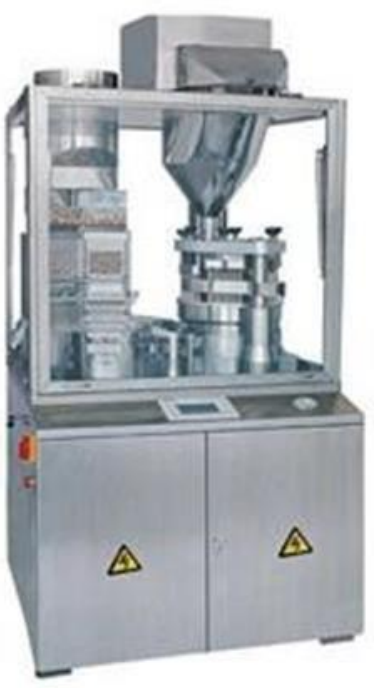

Figura. 5 Máquina llenadora de cápsulas de gelatina dura

Fuente: http://www.tuinventas.com/attachments/article/356/cápsulas\%20duras.pdf 


\section{Conclusiones.}

Al finalizar el presente trabajo, se presenta las conclusiones más importantes:

Se cree que las alternativas seleccionadas cumplen satisfactoriamente con el objetivo principal planteado que es diseñar una máquina encapsuladora automática de comprimidos de gelatina dura de $500 \mathrm{mg}$ utilizando materia prima existente en el país.

El plato debe contar con 10 agujeros para poder dosificar 2400 capsulas por minuto como se estimó.

Es importante realizar un estudio previo de las propiedades físico-químicas de los fluidos a dosificar para determinar las velocidades y una elección adecuada del cilindro de dosificación.

Para el sistema de control de la máquina, resulta más conveniente, un sistema electroneumático, ya que se consigue tener reducción en el número de elementos tanto eléctricos como neumáticos y facilita la diagramación y su complejidad.

La utilización de acero inoxidable en los diferentes elementos de la máquina sobre todo los cuales están más en contacto con el fluido a dosificar, garantiza que el procesos de dosificado sea higiénico, logrando que el fluido no se contamine.

\section{Bibliografía.}

SHIGLEY J. E.; Diseño en ingeniería mecánica; Mc. Graw Hill; Cuarta Edición; México; 1989. NORTON ROBERT; Diseño de máquinas; Segunda edición; Barcelona; España; 1950.

ROBERT L. MOTT; Mecánica de fluidos Aplicada; Ed. Pearson; Cuarta Edición; México. HOLMAN J.P.; Transferencia de calor; $1^{\circ}$ edición en español. 
ENGUES- MOHREN; El plástico en la industria y moldes para inyección; Tomo 3.

MEYSENBUG C. M. Von, Tecnología de los plásticos para ingenieros, España, 1981.

NEUMANN ALEX \& BOCKOFF FRANK, Welding of plastics, EEUU- Ohio 1959, 1ra edición.

INCROPERA F.; Fundamentos de Transferencia de Calor; Pearson Educación; Cuarta Edición; México; 1999.

EUGENE A. AVALLONE; Marks manual del ingeniero mecánico; Tomo 1; Mc. Graw Hill; México; 1995.

LENT DEANE - SHIGLEY JOSEPH; Análisis cinemático y proyectos de mecanismos; Compilado Biblioteca UPS.

PYTEL-SINGER, Resistencia de los materiales, Cuarta edición.

JOSÉ ROLDAN; Prontuario de mecánica industria aplicada; Editorial Paraninfo.

CALERO ROQUE; Fundamentos de mecanismos y máquinas para ingenieros; Primera edición; España; 1999.

IVAN BOHMAN; Catálogo de aceros de Iván Bohman.

American Gear Manufacturer Association.

FESTO; Catálogo de neumática de FESTO A.G. \& C.O. Cilindros normalizados.

INEN; Código de DibujoTécnico-Mecánico; Quito-Ecuador; 1981. 